\title{
Clinical Value of Patlak Ki Images Extracted From Dynamic 18F-FDG PET/CT For Evaluation of The Relationships Between Disease Activity and Clinical Events in Cardiac Sarcoidosis
}

\section{Masatoyo Nakajo ( $\nabla$ toyo.nakajo@dolphin.ocn.ne.jp )}

Kagoshima University, Graduate School of Medical and Dental Sciences

\section{Satoko Ojima}

Kagoshima University, Graduate School of Medical and Dental Sciences

Hirofumi Kawakami

GE Healthcare

Atsushi Tani

Kagoshima University, Graduate School of Medical and Dental Sciences

Akira Hirayama

GE Healthcare

Megumi Jinguji

Kagoshima University, Graduate School of Medical and Dental Sciences

Takuro Kubozono

Kagoshima University, Gradaute School of Medical and Dental Sciences

Mitsuru Ohishi

Kagoshima University, Graduate School of Medical and Dental Sciences

Takashi Yoshiura

Kagoshima University, Graduate School of Medical and Dental Sciences

Original research

Keywords: Cardiac sarcoidosis, dynamic 18F-FDG-PET/CT, SUV static image, Patlak Ki image

Posted Date: September 11th, 2020

DOI: https://doi.org/10.21203/rs.3.rs-49013/v2

License: () (1) This work is licensed under a Creative Commons Attribution 4.0 International License.

Read Full License 
The authors have withdrawn this preprint from Research Square 